\title{
SEXUAL HARASSMENT IN SCIENCE
}

A survey of 296 Australian science professionals found that one woman in two has been sexually harassed at work. More than one-third of female respondents thought their workplace's sexual-harassment policies were inadequate.

Have you experienced sexual harassment in the workplace?

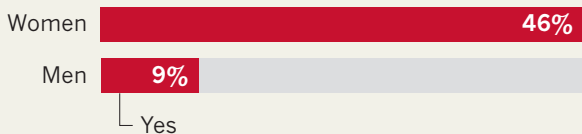
No Preferred not to say

My workplace's policies and procedures are effective at preventing sexual harassment in the workplace.

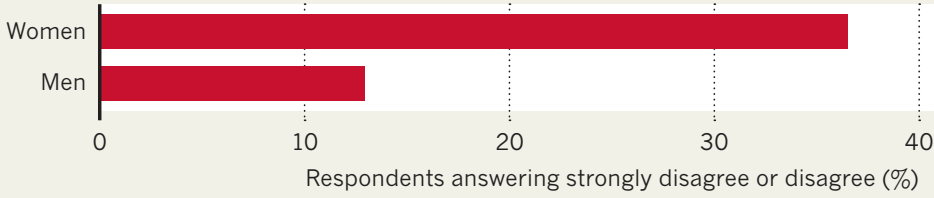

My workplace's policies and procedures are adequate at addressing incidences of sexual harassment.

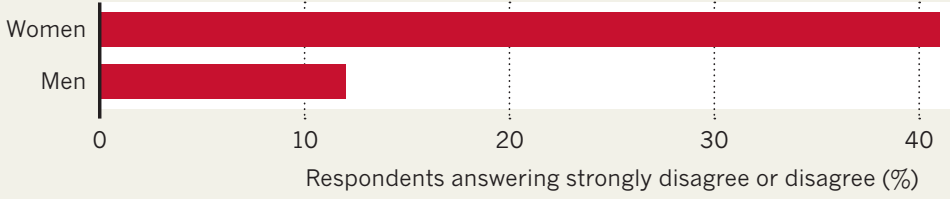

organizations (5\%). The results form part of the STA's submission to a national inquiry into sexual harassment in workplaces, run by the Australian Human Rights Commission.

Female respondents from sexual and gender minority groups (LGBT+) were at the highest risk: 13 out of the 20 women in this group reported experiencing sexual harassment at work. One of the seven male respondents in this group also reported being harassed.

LGBT+ people had even less confidence in their workplace's policies for addressing or preventing sexual harassment than did heterosexual and cisgender respondents. They also felt less safe from reprisals, such as being ridiculed, demoted or forced to resign.

Anna Bull, a sociologist at the University of Portsmouth, UK, and co-founder of the 1752 Group - which addresses the issue of sexual misconduct in higher education - says the results echo the UK experience. "The patterns - particularly LGBTQ people feeling less safe in the workplace, feeling the policies are less adequate, and of course women experiencing high levels of sexual harassment and feeling less protected - these are all very, very familiar findings."

Although the survey numbers were small, and the voluntary nature of the study meant that the sample was self-selecting, Bull says larger studies of sexual-harassment prevalence in higher education have also shown it is a significant problem.

Emma Johnston, president of the STA, described the findings as disturbing, and a "wicked problem". But she says the survey is a step forward in understanding the problem and the urgent need to act.

The survey found that sexual harassment was less common in workplaces with greater gender balance. "That's a very strong, positive message," Johnston says, because it shows that increasing diversity has multiple benefits. Nearly all respondents agreed that addressing sexual harassment in the workplace was important in achieving gender equity in science, technology, engineering and mathematics.

In its report, the STA highlighted the need for scientific workplaces to run accredited training in dealing with sexual harassment. It also pointed out the need for greater awareness of reporting procedures: almost one-third of respondents did not know how to report an incident of sexual harassment at their work. And the report included recommendations such as making it mandatory for employers to report incidents of sexual harassment to national research funding bodies, and stripping funding and professional honours from people found to have committed harassment.

Bull commends the STA for recommending significant punishments for those found to have committed misconduct.

\section{Huge US university cancels subscription with Elsevier}

\section{University of California and publishing giant fail to strike open-access deal.}

\section{BY NISHA GAIND}

$\mathrm{T}$ he University of California - the United States's largest public university system - has cancelled its subscription with Dutch publishing giant Elsevier, after months of negotiations over a proposed deal that would have allowed university researchers to publish in Elsevier journals under open-access terms.

The move is the latest in an escalating global row between scholarly publishers and academic institutions, which are pushing to make more of the scientific literature freely available and say that the costs of publishers' subscriptions are becoming unreasonably expensive.

The University of California (UC) is the first US institution to have completely cancelled its subscription with Elsevier because of such negotiations.

"UC will embolden other institutions to take a hard line," says Joseph Esposito, a senior partner at publishing consultancy Clarke \& Esposito in Washington DC. "Some will be willing to walk away from deals." Esposito argues that pirate-paper site Sci-Hub has undermined the ability of some publishing firms to continue operating as they have before.

UC had been seeking to strike a 'readand-publish' deal that would have allowed its researchers to read papers from the publisher, as well as to publish in Elsevier journals under open-access terms. Conventional licensing deals cover only the cost of accessing paywalled articles.

But the university - which publishes nearly $10 \%$ of US research papers - said on 
- 28 February that it would not renew its contract, because Elsevier was demanding too high a price for the deal. UC's latest subscription with the publisher expired on 31 December, and researchers' access to Elsevier journals had been extended while negotiations continued.

UC pays about US\$11 million a year to Elsevier in subscription fees, and the publisher wanted to increase the cost by about $80 \%$, according to the institution's calculations, said Jeffrey MacKie-Mason, co-chair of the UC negotiating team, in an interview with Berkeley News, a website maintained by the university.

In a statement to Nature's news team, Elsevier called UC's decision "disappointing", and said that it had offered a model in which researchers could publish for free or as open access, and a path to reduce the costs for each UC campus.

In the past few years, stand-offs between academic publishers and institutes have increased in Europe, where several publishers have struck read-and-publish deals with university consortia. Other US institutions, including Florida State University in Tallahassee, have cancelled major subscription deals with Elsevier over concerns about costs, but have continued to pay for access to a small subset of journals.

Researchers in European countries, including Sweden and Germany, have been without access to new papers in Elsevier journals for months, while national library consortia try to negotiate deals.

\section{SHORT-TERM PAIN}

Some UC researchers welcomed the institution's decision. "I'm ecstatic," says Jeffrey Ross-Ibarra, a plant geneticist at the University of California, Davis. He predicts some "short-term pain" as researchers determine how to access articles without a subscription.

Jay Keasling, a chemical engineer at UC Berkeley, has mixed feelings about the situation. Many students and scientists won't have access to publications, he says. But "Elsevier is a bit of a monopoly and I totally get where the university is coming from," he says. "I wish they could have gotten to some point of agreement." Keasling, co-editor-in-chief of an Elsevier journal, Metabolic Engineering, also worries that the break will affect the quality of the publisher's titles.

UC academics will still have access to much of Elsevier's back catalogue and will lose access only to articles published in Elsevier journals since the expiry of the institution's licence, because of contract clauses that cover 'post-termination access'.

Elsevier, headquartered in Amsterdam, publishes nearly 3,000 journals, which issue about 400,000 papers a year. UC has 10 campuses and says that $18 \%$ of its researchers' published studies are in Elsevier journals. .

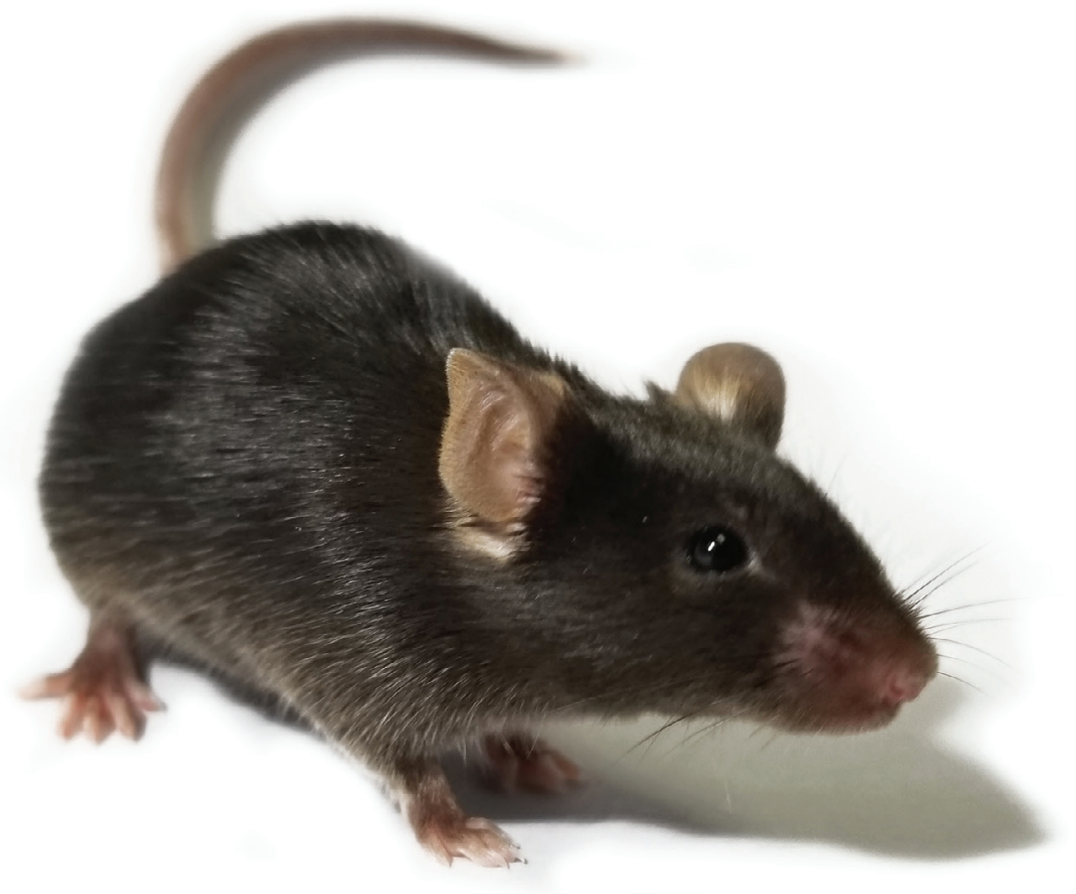

Engineered mice were able to see infrared light as visible light.

\section{ENHANCEMENT}

\section{'Super-mice' see in the dark}

\section{BY MATTHEW WARREN}

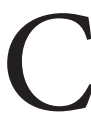

ue the super-mouse. Scientists have engineered mice that can see infrared light normally invisible to mammals including humans.

To do so, they injected into the rodents' eyes nanoparticles that convert infrared light into visible wavelengths (Y. Ma et al. Cell http:// doi.org/gfv5c8; 2019). Infrared light has wavelengths slightly longer than red light between 700 nanometres and 1 millimetre.

Tian Xue, a neuroscientist at the University of Science and Technology of China in Hefei, and his colleagues developed nanoparticles that transform infrared wavelengths into visible light. The nanoparticles absorb photons at wavelengths of around 980 nanometres and emit them at shorter wavelengths, around 535 nanometres, corresponding to green light.

Xue's team attached the nanoparticles to proteins that bind to photoreceptors - the cells in the eye that convert light into electrical impulses - and then injected them into the mice.

The researchers showed that the nanoparticles successfully attached to the photoreceptors, which in turn responded to infrared light by producing electrical signals and activating the visual-processing areas of the brain.

\section{NIGHT-VISION GAMES}

The team conducted experiments to show that the mice did actually detect and respond to infrared light.

In one test, they gave mice the choice between a dark box and a box 'illuminated' with infrared light. Normally, mice - which are nocturnal - will seek out the safety of a darker box. The ordinary mice showed no preference between the two boxes because they couldn't see the infrared light. But the modified mice favoured the dark box.

In another experiment, the team taught both types of mouse to associate green light with an electric shock. The modified mice also froze in fear when an infrared light was turned on.

Finally, the researchers placed the rodents in a water maze that had two arms illuminated by different light patterns, only one of which led to a hidden, dry refuge. The modified mice chose the correct arm of the maze according to the light pattern, regardless of whether the patterns were displayed in visible or infrared light. 